\section{Hydrophilic Polymers and Wetting Agents Affect Absorption and Evaporative Water Loss}

\author{
Allyson M. Blodgett', David J. Beattie ${ }^{2}$, and John W. White ${ }^{3}$ \\ Department of Horticulture, The Pennsylvania State University, University \\ Park, PA 16802 \\ George C. Elliott ${ }^{4}$ \\ Department of Plant Science, University of Connecticut, Storrs, CT 06269
}

Additional index words. container capacity, subirrigation, hydrogels, surfactant, soilless medium

\begin{abstract}
A plantless system using subirrigation was developed to measure water absorption and loss in soilless media amended with hydrophilic polymers, a wetting agent, or combinations of these amendments. Peat-perlite-vermiculite and bark-peat-perlite controls achieved $67 \%$ and $52 \%$ of container capacity, respectively, after 20 daily irrigation cycles. Maximum water content of amended media was $78 \%$ of container capacity. Adding only a hydrophilic polymer did not increase total water content significantly. Adding a wetting agent increased water absorption in both media. However, when hydrophilic polymer and wetting agent were present, the medium absorbed more water than with wetting agent alone. More extractable water was removed from media containing wetting agent. Water loss rate by evaporation was not affected significantly by medium, hydrophilic polymer, wetting agent, or any combination of these variables.
\end{abstract}

Hydrophilic polymers and wetting agents have been used by the nursery and floriculture industries to improve the water-holding capacity of growing media. However, the interaction of these media adjuvants has not been studied thoroughly. Hydrophilic polymers are long-chain, cross-linked organic molecules that increase medium water-holding capacity for bedding (Gehring and Lewis, 1980 Lamont and O'Connell, 1987) and potted plants (Still, 1976). Polymers absorb water at irrigation and release it as the soil surrounding the polymer dries. The polymer, however, has no effect on the physical characteristics of water (Powell, 1987). Wetting agents promote wetting in soilless media by decreasing the surface tension of water. This action allows water to be absorbed more evenly within the medium matrix without altering the physical characteristics of the medium (Powell, 1987). The effect of a wetting agent on a polymer's absorption capacity is not known. Since wetting agents often are included in the manufacture of commercial potting media, any interactive effects should be considered.

Received for publication 8 June 1992. Accepted for publication 23 Jan. 1993. Contribution no. 188 , Dept. of Horticulture, The Pennsylvania State Univ. We thank Aquatrols Corp. of America, Pennsauken, N.J., for financial and material support and W.R. Grace \& Co., Cambridge, Mass., for material support. The cost of publishing this paper was defrayed in part by the payment of page charges. Under postal regulations, this paper therefore must be hereby marked advertisement solely to indicate this fact. 'Graduate Assistant.

${ }^{2}$ Associate Professor.

${ }^{3}$ Professor.

${ }^{4}$ Assistant Professor.
Subirrigation effectively recycles nutrients and reduces water use (Holcomb et al., 1992). In subirrigation, water is distributed upward by capillarity. Most soilless media have high percentages of hard-to-wet organic components such as peatmoss and bark. Therefore, rapid initial wetting and rewetting at irrigation are vital to reduce plant stress.

The objectives of this research were to describe the effects of a wetting agent and hydrophilic polymer on water absorption through subirrigation, retention, and evaporative water loss in two soilless media, and to determine whether there is an interactive effect of wetting agent and hydrophilic polymer.

To examine the absorption characteristics of hydrophilic polymers and the interaction of a wetting agent with absorption, direct in vitro tests were conducted in which SuperSorb-C (SS) hydrophilic polymer was hydrated with a solution of AquaGro-G (AG) wetting agent (both from Aquatrols Corp. of America, Pennsauken, N.J.) and distilled water. AG was used at $0.83 \mathrm{~g} \cdot$ liter $^{-1}$ distilled water, a rate that reflected the manufacturer's specification of $830 \mathrm{~g} \cdot \mathrm{m}^{-3}$ for use with potted crops. As a control, SS was hydrated with distilled water.

A manually controlled subirrigation system similar to that described by Elliott (1992a) was set up. The two base potting mixes consisted of 2 peat: 1 perlite: 1 vermiculite (PPV) and 1 bark : 1 peat :1 perlite (BPP) (both by volume). The materials used for the mixes were sphagnum peat (Fafard Peat Moss Co., Shippegan, N.B., Canada), composted pine bark (W.R. Grace andCo., Cambridge,Mass.), perlite, and vermiculite (Terra-lite; W.R. Grace and Co.). Mixes were amended with SS at 890 $\mathrm{g} \cdot \mathrm{m}^{-3}$ or Soil Moist (SM) (JRM Chemical
Division, Hudson, Ohio) at $710 \mathrm{~g} \cdot \mathrm{m}^{-3}$, or they remained nonamended. SS is a copolymer acrylamide acrylate and SM is a cross-linked modified acrylic polymer. Each of the mixes, including polymer treatments and nonamended mix, were amended with $\mathrm{AG}$ at $830 \mathrm{~g} \cdot \mathrm{m}^{-3}$, or they remained nonamended. SS, SM, and AG rates were based on manufacturers' recommendations for potted crops. To reduce the effects of water-borne salts, which reduce uptake of water by hydrophilic polymers (Bowman et al., 1990; Foster and Keever, 1989), the medium was irrigated with distilled water.

Four replications of each medium treatment were placed in $1050-\mathrm{ml}(12-\mathrm{cm})$ standard pots. The pots were placed in the subirrigation system, which was housed in a controlled-atmosphere growth room at $21 \pm$ 2C. A completely randomized design was used with a split-plot arrangement of treatments. AG treatments were irrigated from water reservoirs separated from the other treatments to avoid contamination of irrigation water by AG leachate.

All pots initially were irrigated overhead, not to achieve container capacity, but to establish capillarity throughout the medium and allow easier upward movement of water in the subsequent subirrigation cycles. After $24 \mathrm{~h}$, the pots were weighed, subirrigated for $1 \mathrm{~h}$, and reweighed. Extractable water (EW) was removed by a vacuum rated at $540 \mathrm{~cm} \mathrm{H}_{2} \mathrm{O}$ at $15.5 \mathrm{C}$, and the pots were weighed. Vacuum suction was applied to each pot for $\leq 10 \mathrm{sec}$.

After 20 daily 1-h subirrigation cycles, all pots were placed in a pan of water and the medium was allowed to saturate completely. After $24 \mathrm{~h}$, the pots were removed from the pans, allowed to drain for $1 \mathrm{~h}$, and weighed. At this point, the medium was considered to be at container capacity (White and Mastalerz, 1966). The pots were moved to a growth chamber at $24 \pm 1 \mathrm{C}$ to evaluate treatment effects on the rapidity of medium water loss by evaporation. Pots were weighed every $2 \mathrm{~h}$ for the first $12 \mathrm{~h}$, and then once daily for 20 days, at which time weight loss had stopped.

Before subirrigation, bulk density and aeration and water retention porosity were measured on nontreated PPV and BPP using methods described by Spomer (1979). Physical properties were determined using a standard $750-\mathrm{ml}$ pot. Because of the differences in absorption between PPV and BPP, the data collected during the experiment were separated according to medium for statistical analysis. SAS (1985) software was used for statistical analysis, which included calculated treatment means, analysis of variance, and mean separation by Wailer-Duncan $\mathrm{k}$ ratio t test.

Absorption tests. SS absorbed slightly more distilled water than AG solution in direct in vitro absorption tests (Fig. 1). Therefore, AG does not enhance absorption by SS in direct tests.

The rapid increase in water content of the medium in all treatments stabilized after 3 to 5 subirrigation cycles (Figs. 2 and 3). Container capacity of the medium, as defined by White and Mastalerz (1966), was not achievedeven after 20 daily subirrigations (Table 1). 
Although hysteresis was expected, water content of both media for any treatment was never $>78 \%$ of container capacity after 20 subirrigation cycles, and was as low as $47 \%$. Elliott (1992b) also reported that with sphagnum peat-granulated rockwool media, container capacity was not achieved after repeated subirrigations. The fact that container capac-

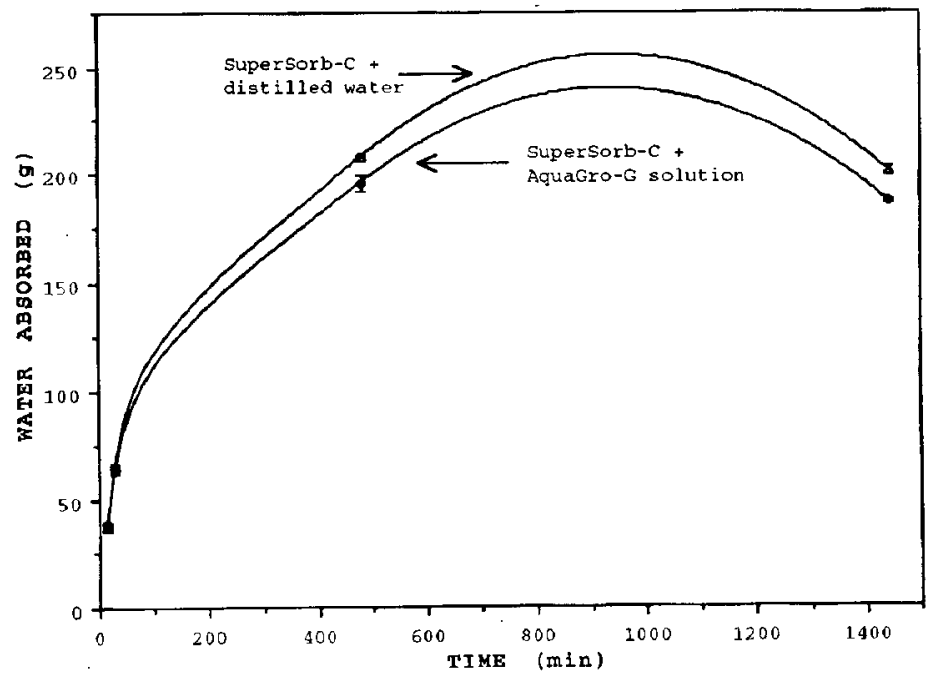

Fig. 1. Absorption curve for in vitro tests of SuperSorb-C in AquaGro-G plus distilled water solution and distilled water control.

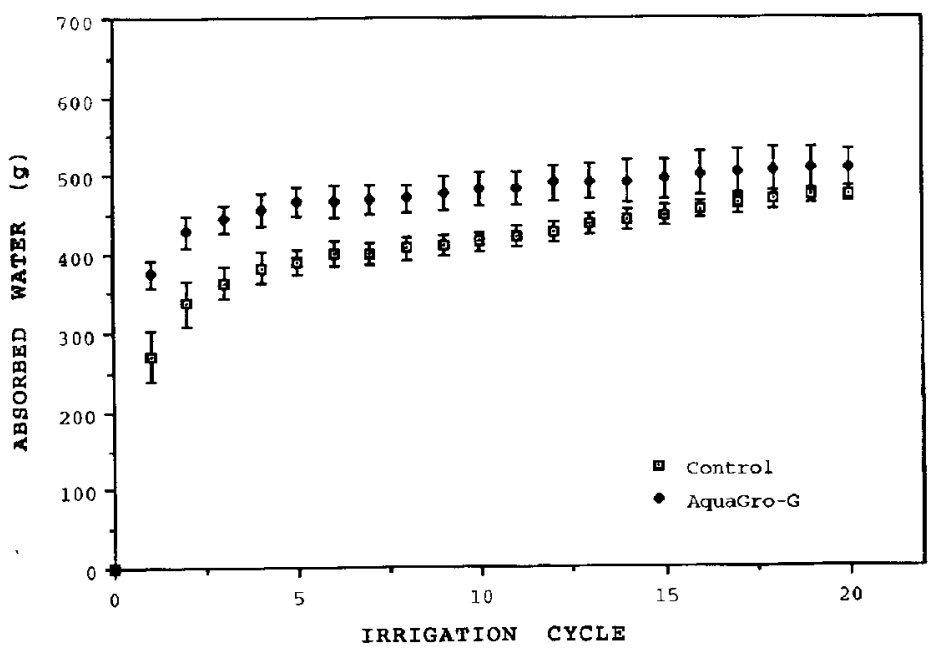

Fig. 2. Absorption curve for peat-perlite-vermiculite medium control and that treated with AquaGro-G.

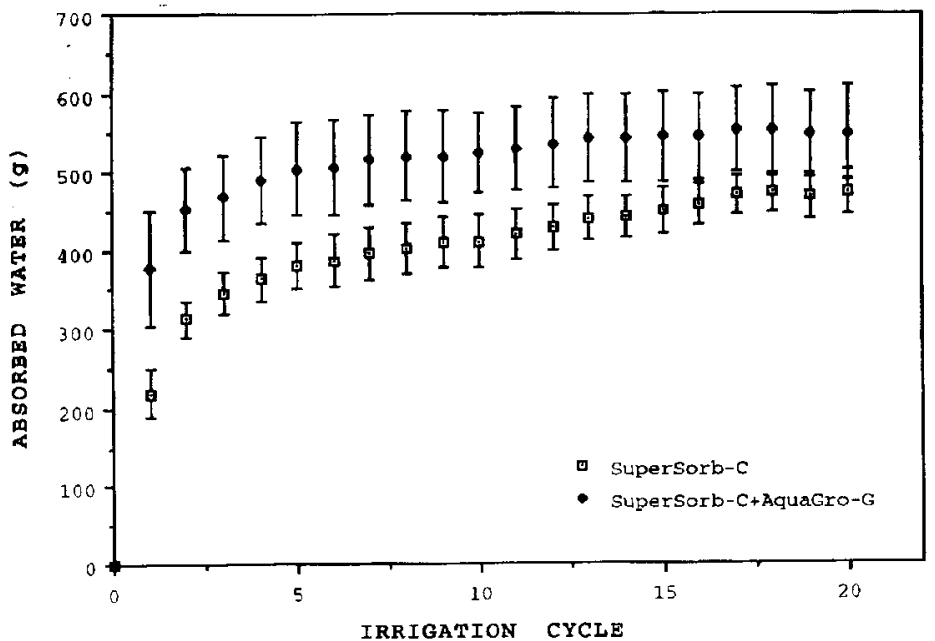

Fig. 3. Absorption curve for peat-perlite-vermiculite medium treated with SuperSorb-C and SuperSorb-C plus AquaGro-G.

ity was not achieved with subirrigation indicates that subirrigation may not exploit fully the water absorption capacity of a medium with or without a hydrophilic polymer. The lack of thorough saturation of the medium with a single subirrigation cycle, even after an initial overhead irrigation to establish capillarity, suggests that plant material transplanted into a dry medium maybe subject to drought stress during the first few days of subirrigation.

Overall porosity (by volume) was similar for both media, although that of BPP $(76 \%)$ was slightly higher than that of PPV (75\%). PPV had art aeration porosity of $19 \%$ and water retention porosity of $56 \%$ (both by volume); BPP, $16 \%$ and $60 \%$, respectively. These physical properties were not reflected in subirrigation trials in which PPV absorbed more water than BPP. This result suggests that the traditional method of measuring container capacity and other physical properties relating to water retention may not apply to the type and amount of absorption that occurs during subirrigation. The PPV control absorbed more water with daily subirrigation than the BPP treatment or control. Amended PPV, except SM plus AG, had a higher water content at container capacity than the corresponding BPP treatment (Table 1).

The absorption pattern was similar for all treatments in both media, but water content varied among treatments (Figs. 2 and 3). Absorption patterns for all treatments were similar; thus, the pattern probably was related to irrigation method, not medium adjuvants.

For all treatments in both media, at least $45 \%$ of the final water content (after 20 daily subirrigations and before saturation) was $a b-$ sorbed in the initial subirrigation cycle (Figs. 2 and 3). After the first cycle, the differences among treatments in the percentage of total water absorbed in a single cycle decreased. Therefore, it was the absorption that occurred during the frost subirrigation cycle that determined the differences in water content after the final subirrigation cycle.

PPV containing AG absorbed significantly more water in the first irrigation cycle compared to treatments without AG (Figs. 2 and $3)$. There were no significant differences in water absorption between the control and the two polymer treatments. The general trend in subsequent irrigations was that the AGamended medium consistently absorbed more water than other media. Clearly, AG was responsible for increased water absorption.

Adding only AG to BPP did not increase water absorption significantly, but adding AG to both SS- and SM-amended BPP significantly increased water absorption compared to SS or SM-amended BPP alone. The absorption curve patterns and relative significant differences for SS plus AG and SM plus AG in BPP (data not shown) were similar to those of SS plus AG in PPV (Fig. 3).

$E W$. Bunt (1988) described easily available water as 10 to $50 \mathrm{~cm} \mathrm{HO}$ at $15.5 \mathrm{C}$ and the matric potential at which potted plants are normally grown as 10 to $100 \mathrm{~cm} \mathrm{H}_{2} \mathrm{O}$. The pressure used in this experiment was high (540 
$\mathrm{cm} \mathrm{H}_{2} \mathrm{O}$ ) to remove any water from the medium that might be available to a plant.

In general, the largest amount of PPV was present in the AG treatments. There were no significant differences in EW among control, SS, and SM treatments (Table 2). In BPP, the same EW trends existed as in PPV; AGamended media contained significantly more EW than those without wetting agent. The additional EW available in media treated with AG does not necessarily imply that these treatments contain additional water. Rather, the results indicate only that this water was extracted more easily from the media by vacuum and, therefore, may be extracted more easily by a plant root. Since wetting agents increase absorption and improve drainage, we expected more water to be extracted from a medium containing wetting agent.

Evaporative loss. Since PPV with all treatment combinations held more water at container capacity than BPP, except in BPP treated with SM plus AG, the PPV evaporative loss curves began at higher water content values. The average amount of water retained in the medium for each treatment is represented by the $y$ intercept of the regression equation of each treatment's water loss curve (Table 3 ). However, water loss rate, represented by the slope of the line, was similar for all treatments in both media, indicating that the presence of $\mathrm{SS}, \mathrm{SM}$, or AG did not retard or promote the release of water from the medium matrix through evaporation. A $t$ test (Steel and Torrie, 1960) on both media indicated that there were no significant differences between slopes of all regression equations for each medium. Therefore, on average, the rate of water released from one treatment was no faster than for any other treatment.

The plantless system without root, tap water, or fertilizer salt interference was useful in determining medium and adjuvant absorption, retention, and evaporative capabilities. With this model, media water content at any given point could be measured without crop-related interferences. This system allowed us to observe the absorption and water loss patterns of the amended and nonamended media accurately. However, in the presence of salts, as in fertilizer, overall absorption by a polymermay be reduced (Foster and Keever, 1989).

With daily subirrigations, adding SS or SM did not improve medium absorption or retention, therefore, their use alone is not effective. Adding AG improved water absorption and retention of both media. This result was expected, since wetting agents are used often in container production for this purpose.

A combination of AG and either SS or SM resulted in greater water absorption and retention than adding only AG. Although AG suppressed absorption by the polymer in a soilless system, the enhanced absorption in the SS plus AG and SM plus AG treatments most likely resulted from the greater availability of water to the polymer due to increased water absorption into the medium matrix due to $\mathrm{AG}$.

Table 1. Average water content (in grams) of peat-perlite-vermiculite (PPV) and bark-peat-perlite (BPP) media in $12-\mathrm{cm}$ pots, for all treatments, at container capacity and subirrigation container capacity.

\begin{tabular}{|c|c|c|c|c|c|c|}
\hline \multirow[b]{2}{*}{ Amendment $^{2}$} & \multicolumn{3}{|c|}{ PPV medium } & \multicolumn{3}{|c|}{ BPP medium } \\
\hline & $\mathrm{CC}^{y}$ & $\begin{array}{c}\text { Final } \\
\text { irrigation }\end{array}$ & $\begin{array}{c}\text { Percent } \\
\text { CC }^{\mathrm{x}}\end{array}$ & $\mathrm{CC}$ & $\begin{array}{l}\text { Final } \\
\text { irrigation }\end{array}$ & $\begin{array}{c}\text { Percent } \\
\text { CC }\end{array}$ \\
\hline $\mathrm{C}$ & $713 b^{w}$ & 474 & 66.5 & $654 \mathrm{~b}$ & 324 & 49.6 \\
\hline $\mathrm{AG}$ & $668 c$ & 508 & 76.0 & $651 \mathrm{~b}$ & 365 & 56.0 \\
\hline SS & $765 \mathrm{a}$ & 475 & 62.0 & $700 \mathrm{a}$ & 328 & 46.8 \\
\hline $\mathrm{SS}+\mathrm{AG}$ & $706 \mathrm{~b}$ & 549 & 77.8 & $700 \mathrm{a}$ & 407 & 58.2 \\
\hline SM & $750 \mathrm{a}$ & 466 & 62.2 & $645 \mathrm{~b}$ & 318 & 49.3 \\
\hline $\mathrm{SM}+\mathrm{AG}$ & $666 \mathrm{c}$ & 486 & 73.0 & $671 \mathrm{ab}$ & 388 & 57.8 \\
\hline
\end{tabular}

${ }^{2} \mathrm{C}=$ control, $\mathrm{AG}=$ AquaGro-G, $\mathrm{SS}=$ SuperSorb-C, $\mathrm{SM}=$ Soil Moist.

${ }^{y} \mathrm{CC}=$ container capacity.

${ }^{x}($ Fkal irrigation/CC) $\times 100$.

"Each mean based on four samples. Mean separation within columns by Wailer-Duncan k ratio $t$ test, $P=$ 0.05

Table 2. Average amount of extractable water (EW) per pot (in grams) vacuumed from medium after daily subirrigation over 20 irrigation cycles:

\begin{tabular}{|c|c|c|c|c|c|c|}
\hline \multirow[b]{2}{*}{ Medium $^{y}$} & \multicolumn{6}{|c|}{ Amendment $^{2}$} \\
\hline & $\mathrm{C}$ & $\mathrm{AG}$ & SS & $\mathrm{SS}+\mathrm{AG}$ & SM & $\mathrm{SM}+\mathrm{AG}$ \\
\hline \multicolumn{7}{|c|}{$E W$} \\
\hline \multicolumn{7}{|l|}{ PPV } \\
\hline Average & 25.3 & 50.4 & 28.8 & 47.4 & 24.6 & 46.0 \\
\hline SD & 3.7 & 5.0 & 3.4 & 5.0 & 4.0 & 4.6 \\
\hline Percent control & 100 & 199 & 114 & 188 & 97.3 & 182 \\
\hline \multicolumn{7}{|l|}{ BPP } \\
\hline Average & 19.3 & 35.8 & 21.9 & 33.0 & 19.4 & 36.5 \\
\hline $\mathrm{SD}$ & 2.1 & 5.4 & 3.1 & 5.3 & 4.3 & 5.5 \\
\hline Percent control & 100 & 185 & 113 & 171 & 100 & 189 \\
\hline
\end{tabular}

${ }^{2} \mathrm{C}=$ control, $\mathrm{AG}=$ AquaGro-G, $\mathrm{SS}=$ SuperSorb-C, $\mathrm{SM}=$ Soil Moist.

${ }^{ } \mathrm{PPV}=2$ peat $: 1$ perlite $: 1$ vermiculite, $\mathrm{BPP}=1$ bark $: 1$ peat $: 1$ perlite (both by volume).

Table 3. Regression equations for evaporative water loss curves for all treatments.

\begin{tabular}{lcc}
\hline & \multicolumn{2}{c}{ Medium $^{z}$} \\
\cline { 2 - 3 } & \multicolumn{2}{c}{ Regression equation $^{y}$} \\
\cline { 2 - 3 } Amendment $^{\mathrm{x}}$ & \multicolumn{1}{c}{ PPV } & BPP \\
\hline $\mathrm{C}$ & $570.89-1.2448 \mathrm{x}$ & $518.47-1.1507 \mathrm{x}$ \\
$\mathrm{AG}$ & $652.77-1.1112 \mathrm{x}$ & $634.75-1.0823 \mathrm{x}$ \\
$\mathrm{SS}$ & $732.12-1.2814 \mathrm{x}$ & $677.52-1.1203 \mathrm{x}$ \\
$\mathrm{SS}+\mathrm{AG}$ & $672.73-1.2137 \mathrm{x}$ & $694.61-1.1621 \mathrm{x}$ \\
$\mathrm{SM}$ & $708.27-1.1764 \mathrm{x}$ & $492.86-1.1083 \mathrm{x}$ \\
$\mathrm{SM}+\mathrm{AG}$ & $646.90-1.0815 \mathrm{x}$ & $526.72-1.1574 \mathrm{x}$ \\
\hline
\end{tabular}

${ }^{2} \mathrm{C}=$ control, $\mathrm{AG}=$ AquaGro-G, $\mathrm{SS}=$ SuperSorb-C, $\mathrm{SM}=$ Soil Moist.

${ }^{y}$ Calculated by Cricket Graph Software (1986).

${ }^{\times} \mathrm{PPV}=2$ peat: 1 perlite $: 1$ vermiculite, $\mathrm{BPP}=1$ bark: 1 peat: 1 perlite (both by volume).

\section{Literature Cited}

Bowman, D.C., R.Y. Evans, and J.L. Paul. 1990 Fertilizer salts reduce hydration of polyacrylamide gels and affect physical properties of gelamended container media. J. Amer. Soc. Hort. Sci. 115:382-386.

Bunt, A.C. 1988. Media and mixes for containergrown plants. 2nd ed. Unwin Hyman, London.

Cricket Software. 1986. Cricket graph Presentation graphics for science and business. Cricket Software, Malvern, $\mathrm{Pa}$.

Elliott, G.C. 1992a. A pulsed subirrigation system for small plots. HortScience 27:71-72.

Elliott, G.C. 1992b. Imbibition of water by rockwoolpeat container media amended with hydrophilic gel or wetting agent. J. Amer. Soc. Hort. Sci. 117:757-761.

Foster, W.J. and G.J Keever. 1989. Growth medium amendment effects on water-absorbing polymer activity. Alabama Expt. Sta., Auburn Univ. Res. Rpt.(6): 16 .

Gehring, J.M. and A.J. Lewis. 1980. Effect of hydrogel on wilting and moisture stress of bedding plants. J. Amer. Soc. Hort. Sci. 105:51 1-5 13.
Holcomb, E.J., S. Gamez, D. Beattie, and G. Elliott. 1992. Efficiency of fertigation programs for Baltic ivy and Asiatic lily. HortTechnology 2:43-46.

Lamont, G.P. and M.A. O'Connell. 1987. Shelf-life of bedding plants as influenced by potting media and hydrogels. Scientia Hort. 31:141-149.

Powell, D. 1987. Water absorbents vs. wetting agents: What's the difference? Amer. Nurseryman 165(12):59-61

SAS Institute. 1985. SAS user's guide: Statistics. version 5. SAS Institute, Cary, N.C.

Spomer, L.A. 1979. Porosity in container soils. Horticulture facts. Univ. of Illinois at UrbanaChampaign Coop. Ext. Serv. Bul. FL-3-79 (rev. 4/83).

Steel, R.G.D. and J.H. Tome. 1960. Principles and procedures of statistics. McGraw-Hill, New York.

Still, S.M. 1976. Growth of 'Sunny Mandalay' chrysanthemums in hardwood-bark-amended media as affected by insolubilized polyethylene, oxide). HortScience 11:483-484.

White, J.W. and J.W. Mastalerz. 1966. Soil moisture as related to container capacity. Proc. Amer. Soc. Hort. Sci. 89:758-765. 